\title{
Everything Matters
}

by Ron Currie, $J$ r.

Published by The Penguin Group, 2009, 305 pages

Reviewed by:

David Trillizio (dpt@bradley.edu), Director, Orientation \& Advisement, Bradley University

The book Everything Matters is at times conversational, sarcastic, and humorous in nature, yet very touching, causing the reader to self-reflect. The story examines the unique life of protagonist Junior Thibodeau, his family, and others who interact with them, providing a fascinating view of a middle class working family drawn together by their son's extreme intellect. Although this reviewer does not believe this book is the best choice for a new student reading program based on the topics and format, it could be a perfect fit for a higher level sociology or English class or an honors student learning community.

The story begins with the main character, Junior, relating what his life is like in the womb, including his perspective about relying on his mother's umbilical cord and temporary intrusions when his father finds his pregnant wife desirable. Soon after his birth, Junior ponders whether anything he does matters when he learns there is a comet heading toward Earth with the power of 283,824,000 Hiroshima bombs.

Other characters include Junior's mother, Debbie, who is a worrier which affects how she interacts with her children, and who turns to alcohol as a coping mechanism. Junior's father, John Senior, who went to war as a teenager rather than pursuing a career in baseball, works long hours that keep him away from his family. He makes poor decisions but accepts and appreciates the life he leads. Rodney, Junior's brother, is portrayed as a typical child - one who likes to watch television, play video games, spend time outside, and participate in sports. After Junior is born, his mother cannot devote equal time to both children, so Rodney begins spending time with his Uncle Rodney who hosts wild parties laden with alcohol and drugs. Rodney develops a drug addiction and later goes into treatment. All in all, Junior's home life is very complicated.

It is later disclosed that Junior is the fourth most intelligent person in the world. The author includes a variety of instances where this proves to be awkward for Junior, his family, and with those he interacts. While in his grade school's "Gifted and Talented" classroom, Junior is finally able to find someone he can relate to when he meets Amy, an "awkward-looking" girl filled with confidence and bravado. Amy becomes an integral part of Junior's inner circle through the rest of story. The book describes Junior's struggle to find his place in a world that has limited relevance or purpose for him. He grapples with deciding whether he should tell anyone about his intelligence, what would happen if he did, and how others would react.

While the book is short, the author provides adequate character depth without short-changing the reader. The author provides just enough pre-adolescent and adolescent glimpses of Amy and Junior to allow the readers to accept her continuing to stand by Junior during some of his awkward high school years and even frightening life experiences during her college years. The book also deals with coming to terms with significant personal loss and gain in one's life.

As the main character of the story, the author guides the reader through easy-to-follow, enlightening, interesting, sometimes sad, yet delicious details about Junior's thoughts and feelings throughout his life journey. His description of the physical, internal, and emotional frustrations that an insipid young man is forced to deal with are written with the right blend of sarcastic humor, sensitivity, and respect for Junior that leaves the reader hoping for the perfect outcome. This work of 
fiction portrays a deep exploration of characters, including their flaws, in real places and outcomes, both good and bad.

As mentioned earlier, this reviewer does not see this book as the best fit for a common reading program for 17- and 18-years-old first-year college students because the character development aspect of the book is long. Additionally, today's students might have difficulty relating to some of the more complicated life situations described in book. At the same time, juniors, seniors, and/or honors students interested in analyzing Currie Jr.'s. writing style or reflecting on how "everything matters" in their lives will appreciate that this book forces them to ponder the "what if's" of life. 